\title{
Correction to: Warm laser shock micro-heading forming (T2 copper): numerical simulation and experimental research
}

\author{
Qifan Gong ${ }^{1} \cdot$ Xiao Wang $^{1} \cdot$ Tao Zhang $^{1} \cdot$ Xin Hou $^{1} \cdot$ Zongbao Shen $^{1} \cdot$ Huixia Liu ${ }^{1}$
}

Published online: 22 January 2022

๑) Springer-Verlag London Ltd., part of Springer Nature 2022

\section{Correction to: The International Journal of Advanced Manufacturing Technology https://doi.org/10.1007/s00170-021-08334-2}

The original article contained a mistake.

This paper studies the micro-heading forming of $\mathrm{T} 2$ copper under warm conditions. The same research group Zhang et al. study the forming of Al micro-heading at room temperature. Since the SEM pictures were taken together, the shapes of the upsetting head are similar and the SEM morphology pictures are gray and white background color, this paper mistakenly used the SEM morphologies of $\mathrm{Al}$ when using the images. This results in the same as the SEM upsetting morphology of Al Fig. 7a in the related research of $\mathrm{Al}$ micro-heading forming at room temperature, Mechanism and formability of microheading of metal rod by laser dynamic loading (https:// doi.org/10.1016/j.optlastec.2021.107732), published in Optics and Laser Technology. Obviously, the published version of Fig. $6 \mathrm{~b}$ in this paper is incorrect.

The correct Fig. 6 is shown below:

Fig. 6 Formed workpiece (a) simulation; (b) experiment

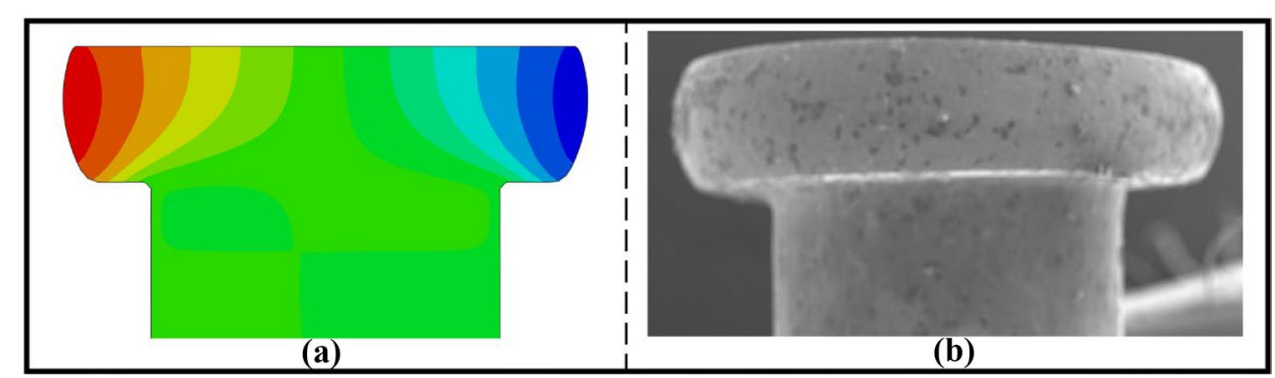

The original article has been corrected.

The original article can be found online at https://doi.org/10.1007/ s00170-021-08334-2.
Publisher's Note Springer Nature remains neutral with regard to jurisdictional claims in published maps and institutional affiliations.

Zongbao Shen

szb@ujs.edu.cn

Huixia Liu

lhx@ujs.edu.cn

Tao Zhang

408633845@qq.com

Xin Hou

2434150014@qq.com
1 School of Mechanical Engineering, Jiangsu University, Zhenjiang 212013, Jiangsu, China 